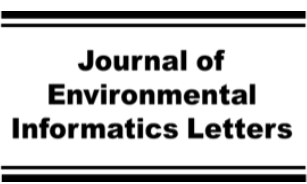

www.iseis.org/jeil

\title{
Automation of Forest Fire Danger Index from the Near Real Time Satellite Datasets
}

\author{
K. V.S. Babu ${ }^{1 *}$ and A. Roy ${ }^{2}$ \\ ${ }^{1}$ International Institute of Information Technology, Hyderabad \& Indian Institute of Remote Sensing, ISRO, Dehradun 248001, India \\ ${ }^{2}$ Indian Institute of Remote Sensing, ISRO, Dehradun 248001, India
}

Received 17 July 2019; revised 23 September 2019; accepted 23 September 2019; published online 30 September 2019

\begin{abstract}
Forest fire is a major ecological disaster, which has economic, social and environmental impacts on humans and also causes the loss of biodiversity. Forest officials issue the warnings to the public on the basis of fire danger index classes. There is no fire danger index for the country India due to the sparsely distributed meteorological stations. In this study, we have made an attempt to integrate both the Static and Dynamic fire danger indices and also used the near real time data sets that can be available for download through Earthdata website after one hour of the satellite overpass and also automated the entire procedure. Static Fire Danger Index (SFDI) is a constant over the study area, computed from the MODIS Land cover type yearly L3 global $500 \mathrm{~m}$ SIN grid (MCD12Q1) and ASTER GDEM datasets. In this study, Dynamic Fire Danger Index (DFDI) has been calculated from the Near Real Time (NRT) Level 2 MODIS Terra Land Surface Temperature datasets (MOD11_L2) and MODIS TERRA NRT surface reflectance dataset MOD09. DFDI has been developed from three parameters i.e., Potential surface temperature, Perpendicular Moisture Index and Modified Normalized Difference Fire Index (MNDFI). Finally, The Forest Fire Danger Index (FFDI) has been developed from the static and dynamic fire danger indices by the additive model and the overall accuracy was ranging from $86 \%$ to $95 \%$ and Area under Curve (AUC) values ranging from 0.81 to 0.91 during the major fire episode of 2018. Thus, the FFDI has been useful to assess the fire danger accurately over the study area and can be useful anywhere, where the meteorological stations are un-available. The procedure of calculating the DFDI and FFDI has been automated in $\mathrm{R}$ studio environment in near real time and therefore, the fire danger maps can be disseminated to fire officials in near real time for the quick actions to suppress the fire activities.
\end{abstract}

Keywords: forest fire, MODIS, forest fire danger index, DFDI, SFDI, MOD14

\section{Introduction}

The Fire Danger indices are used as a tool by decision makers to issue warnings to the public, based on the level of fire danger classes i.e., No danger, Low, Moderate, High and very High, for implementing the mitigation measures to control the fires. The Fire Danger index is an integration of both the dynamic and static fire danger indices. Fire danger indices are broadly classified into two types viz. long-term indices (structural indices) and short-term indices. Long-term indices are indicators of vegetation and topographic conditions as well as the anthropogenic factors that favor the occurrence of forest fires. Long term indices vary periodically like monthly and yearly and gives a clear understand about the spatial pattern of the fire events. Therefore, long-term indices have been used to determine the forest areas with high probability of fire occurrence. The variables for long-term indices are topography (elevation, slope, and aspect), vegetation type, proximity to settlements, distance to the roads, rail networks, and fire history. Whereas, short-term indices mainly consider parameters that changes sud-

* Corresponding author. Tel.: +(91) 7895208605; fax: +(91) 9908734206. E-mail address: sureshbabu.iiith@gmail.com (K. V. S. Babu).

ISSN: 2663-6859 print/2663-6867 online

(C) 2019 ISEIS All rights reserved. doi:10.3808/jeil.201900015. denly and depend on factors influencing ignition and spreading the forest fires. The short-term variables are air temperature, relative humidity, wind speed and rainfall.

Fire Danger Models can be used to predict the probability of occurrence of forest fire based on the forest fuel characteristics, weather and topography. These are used in decision making for better management and control of forest fire. It can also be used as a tool to train and improve skills of firefighters and also to visualize, estimate and explain the behavior of fire, its spread and the control measures. At present, Canadian FWI (Fire Weather Index) approach was adapted in other countries such as Argentina, USA, and Alaska (Alexander and Cole, 2001; Taylor, 2006), Indonesia (De Groot et al., 2007), Malaysia (De Groot et al., 2007), Mexico (Lee et al., 2002); New Zealand (Alexander and Fogarty, 2002), Portugal (San-Miguel-Ayanz et al., 2003), Spain (Viegas et al., 1999) and Sweden (Granström, 2001) around the world for forecasting the fire danger on daily basis. The FWI calculation needs a set of automatic weather station parameters, such as air temperature, wind speed, and relative humidity during the mid-day; and point locations data of 24-h accumulated rainfall. The problem with the FWI is it employs the interpolation techniques, and it is evident that different interpolation techniques (for example, spline, kriging, IDW) may possibly generate different outputs even using the same set of data inputs. In other studies (Molders, 2008; Safi and 
Bouroumi, 2013), statistical Numerical Weather Prediction model was used to calculate the Canadian CFFDRS danger indices and the US NFDRS danger indices at a spatial resolution of one degree to one degree i.e., $\sim 110 \times 110 \mathrm{~km}^{2}$, where the main problem is the low spatial resolution.

In this regard, geospatial techniques are useful with improved spatial and temporal resolutions for monitoring and forecasting the fire danger conditions (Ceccato et al., 2002; Bajocco et al., 2010; Leblon et al., 2017). Understanding the importance of satellite datasets, researchers started using the satellite derived parameters for fire danger estimations. These satellite based products are: "Normalized Difference Vegetation Index (NDVI)" (Leblon et al., 2007), "Enhanced vegetation index (EVI)" (Bisquert et al., 2012, 2014), "Vegetation Index green (VI green)", "Normalized Difference Infrared Index (NDII)" (Peterson et al., 2008; Sow et al., 2013), "Global Vegetation Moisture Index (GVMI)" (Sow et al., 2013), "Visible Atmospheric Resistant Index (VARI)" (Schneider et al., 2008), "Normalized Multiband Drought Index (NMDI)" (Wang et al., 2008) and "Normalized Difference Water Index (NDWI)" (Stow et al., 2005) as well as meteorological vari-ables such as "surface temperature" ( $\mathrm{T}_{\mathrm{S}}$ ) (Oldford et al., 2006; Leblon et al., 2007), air temperature ( $\mathrm{T}_{\mathrm{a}}$ ) (Nieto et al., 2011), Relative Humidity (RH) (Nieto et al., 2011).

The AVHRR-derived NDVI and TS images have been used in the calculation of the fire danger codes of the FWI system i.e., 'Fine Fuel Moisture Content, Duff Moisture Code, Drought Code, BuildUp Index, and 'Fire Weather Index code' (Oldford et al., 2006; Leblon et al., 2007) and the correlation shows that they have similar pattern, but it was observed that there is no direct relationship between these parameters. NDVI and surface temperature $\left(\mathrm{T}_{\mathrm{S}}\right)$ were used to determine the live fuel moisture in the vegetation (Chuvieco et al., 2002). Live moisture can also be determined using greenness indices such as NDVI, VARI, VIgreen, EVI, and NDWI (Dennison et al., 2005; Dasgupta et al., 2007; Peterson et al., 2008) as these indices are more sensitive to changes in water content as well as the chlorophyll status in vegetation (Peterson et al., 2008). MSG-SEVIRI generated weather variables such as Ta and RH were used to determine the dead fuel moisture (Nieto et al., 2011).

Soil moisture is also an indicator for estimating the drought and forest fire danger. Soil moisture is an important variable for the growth of vegetation as well as the plant functionalities (Hari and Nojd, 2009) and indicate the weather and drought conditions in the forests (Fennessy and Shukla, 1999). In general, soil moisture can be estimated from the ground-based methods either direct or indirect, but, direct methods are time consuming and do not have the spatial variability. Surface wetness conditions can be estimated based on the relation between the vegetation index (VI) and Ts, the scatter plot of VI-Ts is to be a triangle or trapezoidal shape and surface wetness was calculated from the edges (Moran et al., 2004; Carlson, 2007; Petropoulos et al., 2009). Hassan et al. (2007) developed the "Temperature Vegetation Wetness Index (TVWI)" by using the potential surface temperature instead of
Ts to eliminate the effect of Terrain elevation and then combined with NDVI (Hassan et al., 2007; Hassan and Bourque, 2009).

In the studies carried out by Schneider (2008) and Huesca (2009), various indices such as "NDVI, VARI, and NDWI" were used as a substitute to live fuel moisture in determining the "fire potential index" (Schneider et al., 2008; Huesca et al., 2009). The results suggested that the indices "VARI" and "NDWI" have shown the best results of measuring the live fuel moisture conditions when compare to the "NDVI". Another index, "Normalized Multiband Drought Index (NMDI)" was used in assessing the drought conditions and can be computed as follows (Wang and Qu, 2007, 2009; Wang et al., 2008).

A very few studies have been carried out on the use of satellite data for the determination of probability of fire occurrence. Vidal and Devaux-Ros (1995) calculated the water deficit index (WDI) by relating NDVI and the difference between $T_{a}$ and $T_{s}$ and it effectively predicted the onset of fires (Vidal and Devaux-Ros, 1995). Guangmeng and Mei (2004) used MODIS-derived surface temperature over the forested regions of northeast China. They observed that surface temperature values were increased at least 3 days before the occurrence of fires, but, the rate of increase of the $T_{s}$ values for fire occurrence were not quantified. Oldford et al. (2003) utilized the NOAA AVHRR-derived $T_{s}$ and NDVI parameters over the northern boreal-forested regions of the Northwest Territories in Canada. The results of the study showed increased trend of the surface temperature values at least 3 days before the fire occurrences similar to previous study (Guangmeng and Mei, 2004), while NDVI did not show any indication of the fire occurrence (Oldford et al., 2003).

Akther and Hassan (2011) utilized the 8-day MODIS derived composites of "surface temperature", "Temperature Vegetation Wetness Index (TVWI)", and NMDI, over the boreal forested regions of Alberta, Canada for the years from 2006 to 2008 (Akther and Hassan, 2011). They found an accuracy of $91.6 \%$ of the fire pixels in "very high" to "moderate" danger classes. Chowdhury and Hassan (2015) used the MODIS derived parameters such as $\mathrm{T}_{\mathrm{S}}$, NDVI, NMDI, and Precipitable Water (PW). They revealed that $95.51 \%$ of the fires fell under "extremely high" to "moderate" danger classes. MODIS TERRA 16-day composite EVI datasets from 2001 to 2006 were used by Bisquert et al. (2012) for the computation of fire occurrence over Galicia, Spain and achieved an overall accuracy of $58.2 \%$ when compared with the actual occurrence of fires.

In light of above discussion, the present study describes the development of satellite-based forest fire danger index for Uttarakhand state of India as it does not have the sufficient number of meteorological stations especially in and around the forest. The developed forest fire danger index is an integration of the static and dynamic fire danger indices. The static fire danger index is based on the static variables like the forest types, topography and terrain characteristics whereas the dynamic fire danger index is based on the dynamic variables like air temperature, moisture conditions.

The forests of Uttarakhand state of India, are prone to forest 
fires, causing loss of biodiversity and degradation of the environment. Most of the valuable plant and animal species are depleted due to the frequent occurrence of forest fires (Babu et al., 2016, 2018) The near real time fire alerts are being generated at National Remote Sensing Centre (NRSC), and Forest Survey of India (FSI) using the Moderate Resolution Imaging Spectroradiometer (MODIS) sensor on TERRA and AQUA satellites and Visible Infrared Imaging Radiometer Suite data from the Suomi National Polarorbiting Partnership (SNPPVIIRS). Active fire location information is disseminated to state forest departments within half an hour after the satellite overpass and also uploaded on the respective website. But hitherto operational fire danger rating system has not been developed in India except zonation of risk areas in protected areas. In this study, an attempt has been made to develop the Forest Fire Danger Index (FFDI) by integrating the static and dynamic fire danger indices by an additive model.

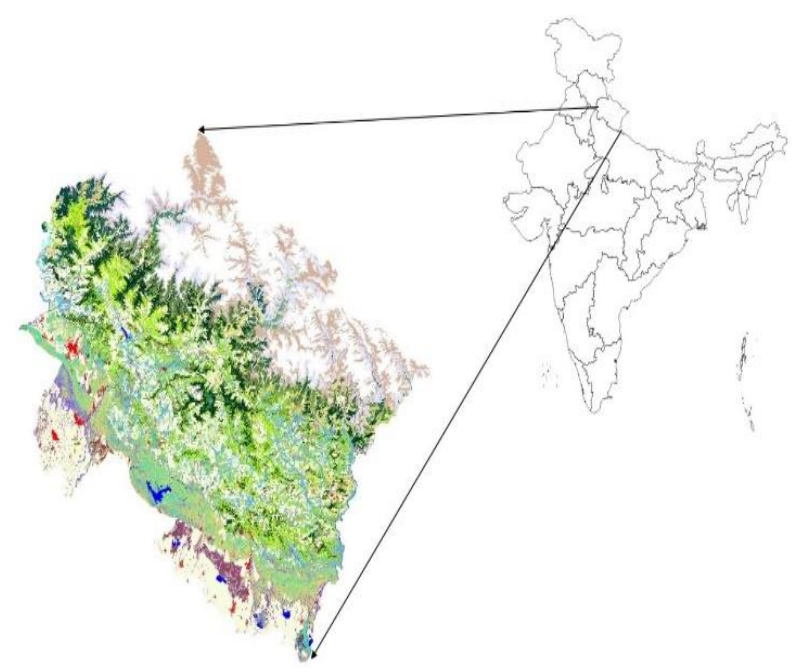

Figure 1. Study area - Uttarakhand state.

\section{Study Area}

Uttarakhand is a hill state in India, which shares an international border with China in the north and Nepal in the east. Uttarakhand lies between $28^{\circ} 43^{\prime} \mathrm{N}$ to $31^{\circ} 27^{\prime} \mathrm{N}$ latitude and $77^{\circ} 34^{\prime} \mathrm{E}$ to $81^{\circ} 02^{\prime} \mathrm{E}$ longitude. It has an area of $53,483 \mathrm{~km}^{2}$ or $10.3 \%$ total geographical area of the Himalaya inhabited by 10.1 million persons living in 16,583 villages and 86 urban centers in 159 density per sq.km. At present, the state is administrated in 2 divisions, i.e., Kumaon and Garhwal comprising 13 districts: Almora, Bageshwar, Nainital, Champawat, Pithoragarh, U S Nagar (Kumaon), Dehradun, Haridwar, Pauri, Tehri Garhwal, Uttarkashi, Chamoli, and Rudraprayag (Garhwal). Further, these districts are divided into 52 Tehsils and 97 development blocks. Districts Haridwar and Udhamsingh fall into a plain area, whereas Nainital and Dehradun falls into both foothills and plain areas and rest nine districts totally lie in hill area. Uttarakhand has recorded forest area of $34,651 \mathrm{~km}^{2}$, which is $64.79 \%$ of its geographical area
(ISFR, 2015) and Figure 1 shows the study area.

Uttarakhand is largely a rocky mountainous region, where the altitudes dramatically fluctuate between 300 to $7,817 \mathrm{~m}$. As a result, high mountain ridges and deep river valleys are common features in the mountain area and great plain in the southern part of the state. This abrupt altitudinal variation has obviously resulted in a complex but interesting diversity in topography, meteorology, flora, fauna, demography etc. from the Gangetic plain in the south a comparatively less elevated rain shadow zone of Trans-Himalaya in the north. The large variations in altitudes, the slope, aspect, presence of glaciers, forests, and its geographical locations has resulted in varying climates in different parts of Uttarakhand state, even at the micro or local levels.

\section{Satellite Datasets}

MODIS is one of the widely used satellite sensors on board NASA TERRA and AQUA satellite datasets that scientists have been using for global and regional studies. Table 1 show the datasets used in this study to develop the Forest Fire Danger Index (FFDI). The datasets were taken during the major fire episode of Uttarakhand state i.e., April 16, 2018 to May 2, 2018.

Table 1. Satellite Datasets

\begin{tabular}{llll}
\hline Name of Datasets & Product ID & $\begin{array}{l}\text { Spatial } \\
\text { Resolution }\end{array}$ & $\begin{array}{l}\text { Temporal } \\
\text { Resolution }\end{array}$ \\
\hline $\begin{array}{l}\text { Land Surface } \\
\text { Temperature }\end{array}$ & MOD11NRT & $1 \mathrm{~km}$ & Daily \\
$\begin{array}{l}\text { Surface } \\
\text { Reflectance }\end{array}$ & $\begin{array}{l}\text { MOD09GA } \\
\text { NRT }\end{array}$ & $500 \mathrm{~m}$ & Daily \\
$\begin{array}{l}\text { Geolocation fields } \\
\text { Digital Elevation }\end{array}$ & MOD03 & $1 \mathrm{~km}$ & Daily \\
$\begin{array}{l}\text { Model } \\
\text { Fire and Thermal } \\
\text { Anomalies }\end{array}$ & MCD14 & $30 \mathrm{~m}$ & - \\
\hline
\end{tabular}

\section{Methodology}

In this study, Dynamic Forest Fire Danger index and Static Fire Danger Index has been integrated to develop the Forest Fire Danger Index. The Static Fire Danger Index (SFDI) was developed from the fuel type danger index, slope danger index, aspect danger index, elevation danger index, and terrain ruggedness danger index. Whereas the Dynamic danger index has been developed from three parameters viz. Potential surface temperature, Perpendicular Moisture Index and Modified Normalized Difference Fire Index using the near real time datasets, available through NASA Earthdata website after one hour of the satellite overpass. Figure 2 shows the methodology of the study.

\subsection{Static Fire Danger Index (SFDI)}

Static Fire Danger Index has been derived from the static parameters i.e., fuel, topographic and terrain characteristics, 
which influence the spread of forest fires. SFDI was computed from the ASTER GDEM dataset and MODIS TERRA \& AQUA land cover type product (MCD12Q1) (Babu et al., 2016 b). The SFDI was computed from the integration of five distinct indices i.e., Fuel type danger index, Terrain ruggedness danger index, Slope danger index, Aspect danger index and Elevation danger index (Babu et al., 2016b). Figure 3 shows the computation of SFDI by using packages raster, rgdal, Rcpp, sp, tiff, jpeg, EBImage, png, and locfit in R studio environment.

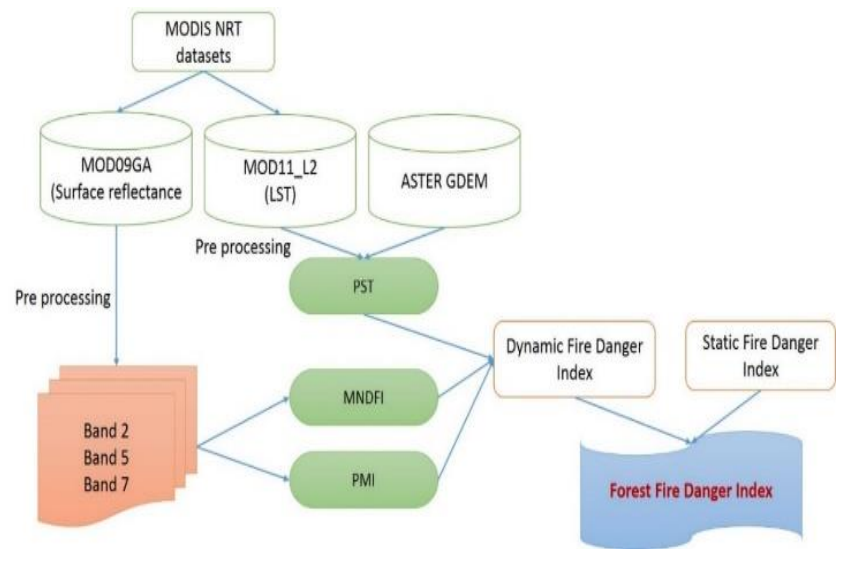

Figure 2. Flow chart showing the methodology.

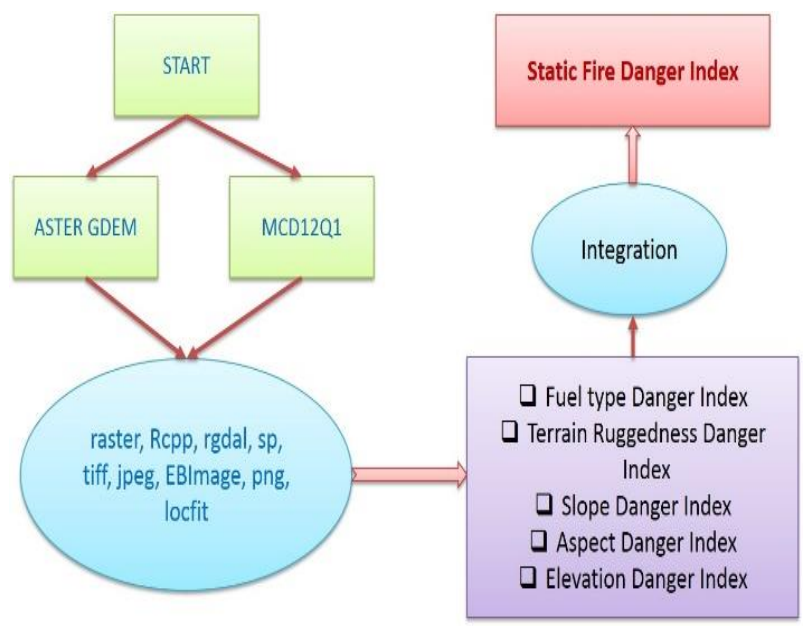

Figure 3. Structure of SFDI.

\subsection{Dynamic Fire Danger Index (DFDI)}

Dynamic forest fire danger index has been developed by integrating three parameters such as potential surface temperature, Perpendicular Moisture Index (PMI) and Modified Normalized Difference Fire Index (MNDFI), which were derived from the MODIS TERRA and ASTER DEM satellite datasets. Uttarakhand has variable hilly terrain so, elevation influences the Land Surface Temperature (LST) because LST decreases with the increase of elevation due to the pressure drops with the increasing of elevation. Hence, Potential Surface Temperature (PST) i.e., terrain corrected temperature has been computed from the Near Real Time (NRT) Level 2 MODIS Terra Land Surface Temperature datasets (MOD11_L2) and ASTER GDEM using the Barometric formula. MODIS TERRA NRT surface reflectance dataset MOD09 has been used for generating the PMI and MNDFI.

This methodology has been taken from our previously published work (Babu et al., 2016a). The main difference from the previous work is temporal resolution and the level of satellite dataset processing. In this study, Near Real Time datasets have been used instead of the 8-day composite datasets. These near real time datasets are available within 1 hour of the observation time of satellite overpass, downloaded through an FTP website. In this study, individual parameters were computed and have assigned the danger values from 1 to 5 based on the danger classes. The DFDI has been computed by adding the individual parameters i.e., PST, PMI and MNDFI.

LANCE (The Land, Atmosphere Near Real Time Capability for EOS) supports the application users across the globe, who are working on the monitoring of natural resources and managing the disasters. LANCE NRT data available much quicker than general processing time, including the data and imagery from the sensors such as MODIS, AIRS, AMSR2, MISR, MLS, MOPITT, OMI, OMPS, and VIIRS (Earthdata website). DFDI has been computed from the Near Real Time (NRT) MODIS TERRA datasets, available through ftp server (ftp://nrt3.modaps.eosdis.nasa.gov/). Figure 4 shows the workflow to compute the DFDI in near real time by using $\mathrm{R}$ studio environment.

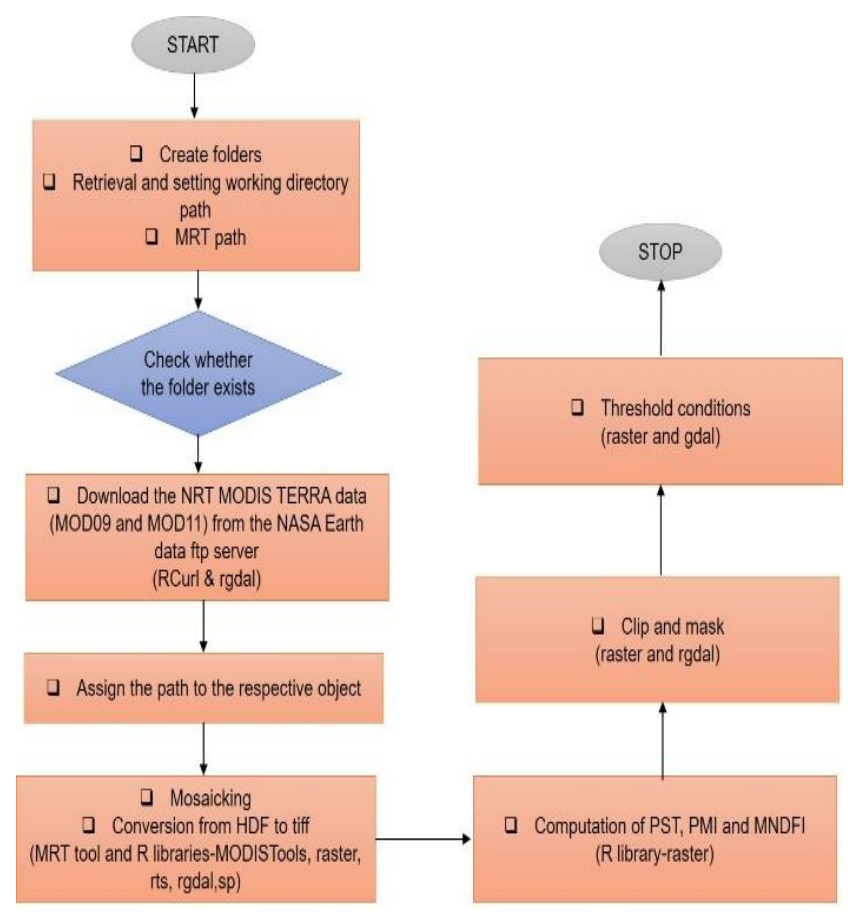

Figure 4. Workflow diagram of DFDI.

In the first step, MODIS NRT datasets can be downloaded from the http site or Earthdata website in tiles format. The Ut- 
tarakhand state covers in 4 MODIS tiles i.e., h24v05, h24v06, h25v05, and h25v06. MOD09GA and MOD11_12 data can be downloaded tiles wise and saved into local directory for further analysis. The downloaded MODIS datasets are in HDF-EOS format and in different 4 tiles for the Uttarakhand. The datasets have to be converted into easily readable format i.e., GeoTIFF and also mosaic to get the datasets in a single seamless file. MOD09 consists of several parameters such as Bands from 1 to 7 in $500 \mathrm{~m}$ spatial resolution, information about the band quality, solar zenith angle, view zenith angle. Bands 2, 5, and 7 are required to compute the indices PMI and MNDFI. MODIS Reprojection Tool (MRT), an open source tool developed by LPDAAC, has been used to read the hdf files. Next step shows the entire preprocessing of MODIS NRT datasets in R studio environment.

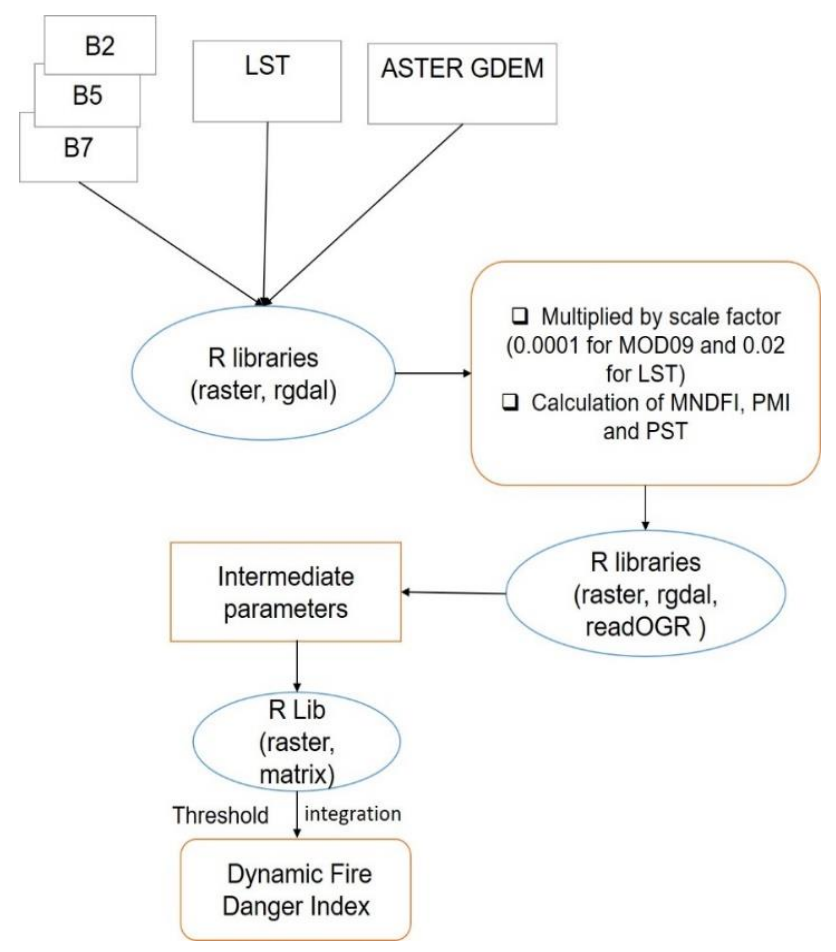

Figure 5. Steps involved in calculation of DFDI.

MOD11 dataset consists of the parameters such as land surface temperature (LST) of day and night, emissivity of band 31 and band 32, view time of day and night etc. The LST of day time has been extracted from MOD11 in similar way as like spectral bands. After getting the required datasets i.e., LST, Bands 2, 5, and 7 for each day, have been used to calculate the parameters PST, MNDFI, and PMI. The MODIS reflectance bands have to be multiplied by the scale factor 0.0001 to get the surface reflectance of B2, B5 and B7. Figure 5 shows the calculation of intermediate parameters and finally calculation of DFDI.

PMI (Maffei and Meneti, 2014) and MNDFI (Vermote et al., 2002; EijiNunohiro et al., 2007) has been calculated by using the Equations 1 and 2 respectively:
$P M I=-0.73 \times(R 5-0.94 R 2-0.028)$

$M N D F I=\left[\frac{\text { Band } 7-\text { Band } 2-5 \%}{\text { Band } 7+\text { Band } 2+5 \%}\right]$

where R5 and R2 are the MODIS spectral bands 5 and 2 respectively.

PST can be computed from the MOD11_L2 NRT datasets by using the Barometric formulae:

$p=p_{0}\left(1-\frac{L z}{T_{o}}\right)^{\frac{g M}{R L}}$

$\theta_{s}=T_{s}\left[\frac{p_{0}}{p}\right]^{\frac{R}{C p}}$

\subsection{Forest Fire Danger Index (FFDI)}

The FFDI has been calculated by integrating the static fire danger index and individual dynamic forest fire danger index on each day because each index has its own influence on fire danger. The FFDI has been categorized into 5 fire danger classes such as "very high, high, moderate, low and no fire danger" and Table 2 shows the value of forest fire danger and the corresponding danger classes.

Table 2. Fire Danger Classes Assigned to FFDI

\begin{tabular}{lll}
\hline S No & Forest Fire Danger Index value & Danger class \\
\hline 1 & $\leq 8$ & No fire danger \\
2 & $9 \sim 16$ & Low \\
3 & $17 \sim 24$ & Moderate \\
4 & $25 \sim 32$ & High \\
5 & $>32$ & Very High \\
\hline
\end{tabular}

\section{Results and Discussion}

MODIS active fire hotspots have been used for validating the fire danger model in various studies as a proxy for the actual occurrence of fires (Chuvieco et al., 2008; Maeda et al., 2011; Adab et al., 2013; Eskandari and Chuvieco, 2015; Babu et al., 2016a, b). Similarly, in the present study, MODIS active fire product MCD14 has been used for the validation. FFDI has been computed daily by integrating both SFDI and DFDI after computing the DFDI from the NRT MOIDS TERRA datasets and categorized into 5 classes based on the threshold conditions as shown in Table 2. Figure 6 shows the forest generated fire danger maps overlaid with the fire hotspots during the major fire episode in 2018.

\subsection{Fire Danger Index (FDI) - Validation}

The number of fire hot spots in each fire danger class from no fire to very high danger classes were extracted. It would be 

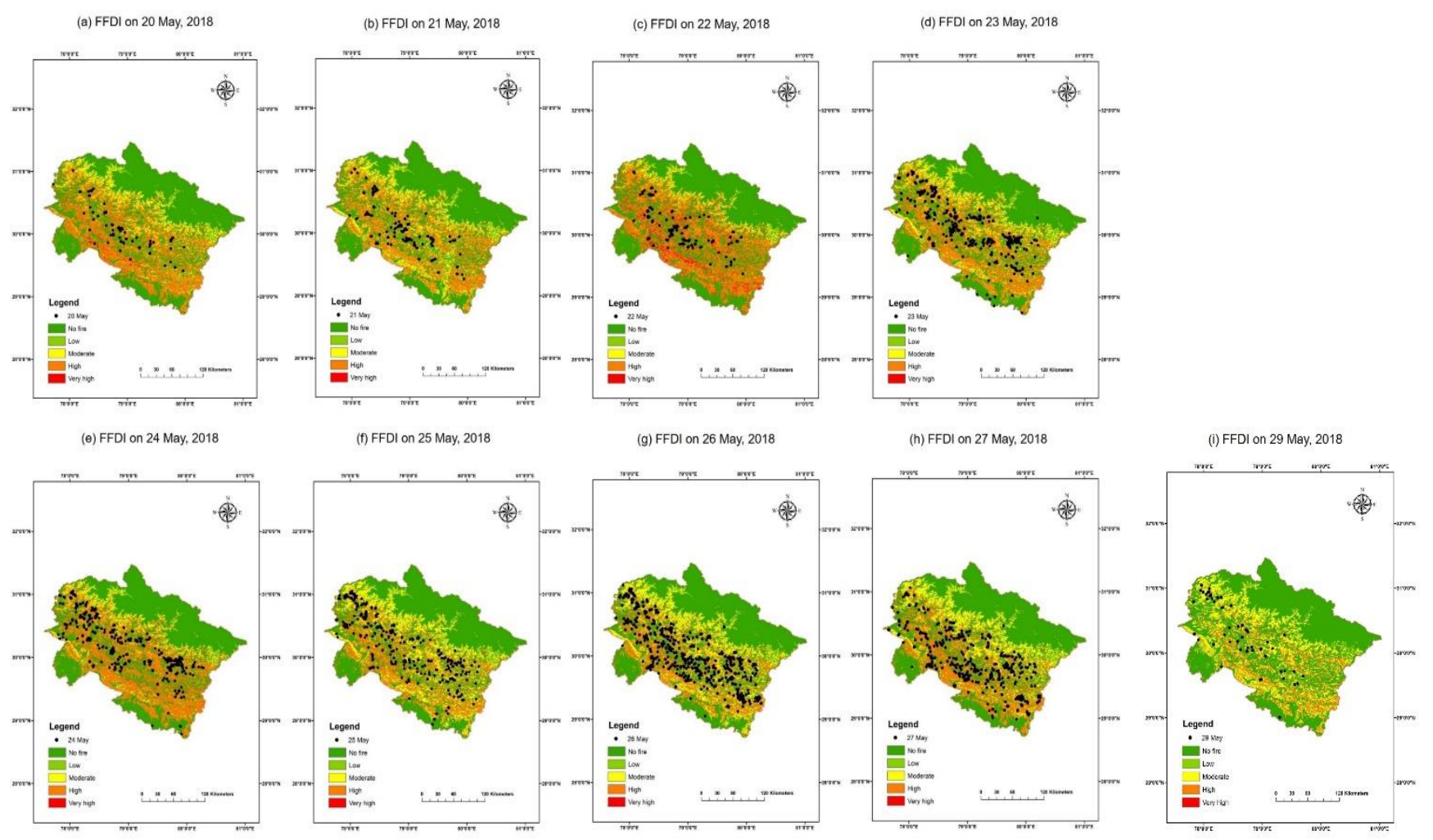

Figure 6. Forest Fire Danger Index images of 2018 were overlaid with corresponding active fire location data. (a) 20 May, (b) 21 May, (c) 22 May, (d) 23 May, (e) 24 May, (f) 25 May, (g) 26 May, (h) 27 May, (i) 29 May, 2018.
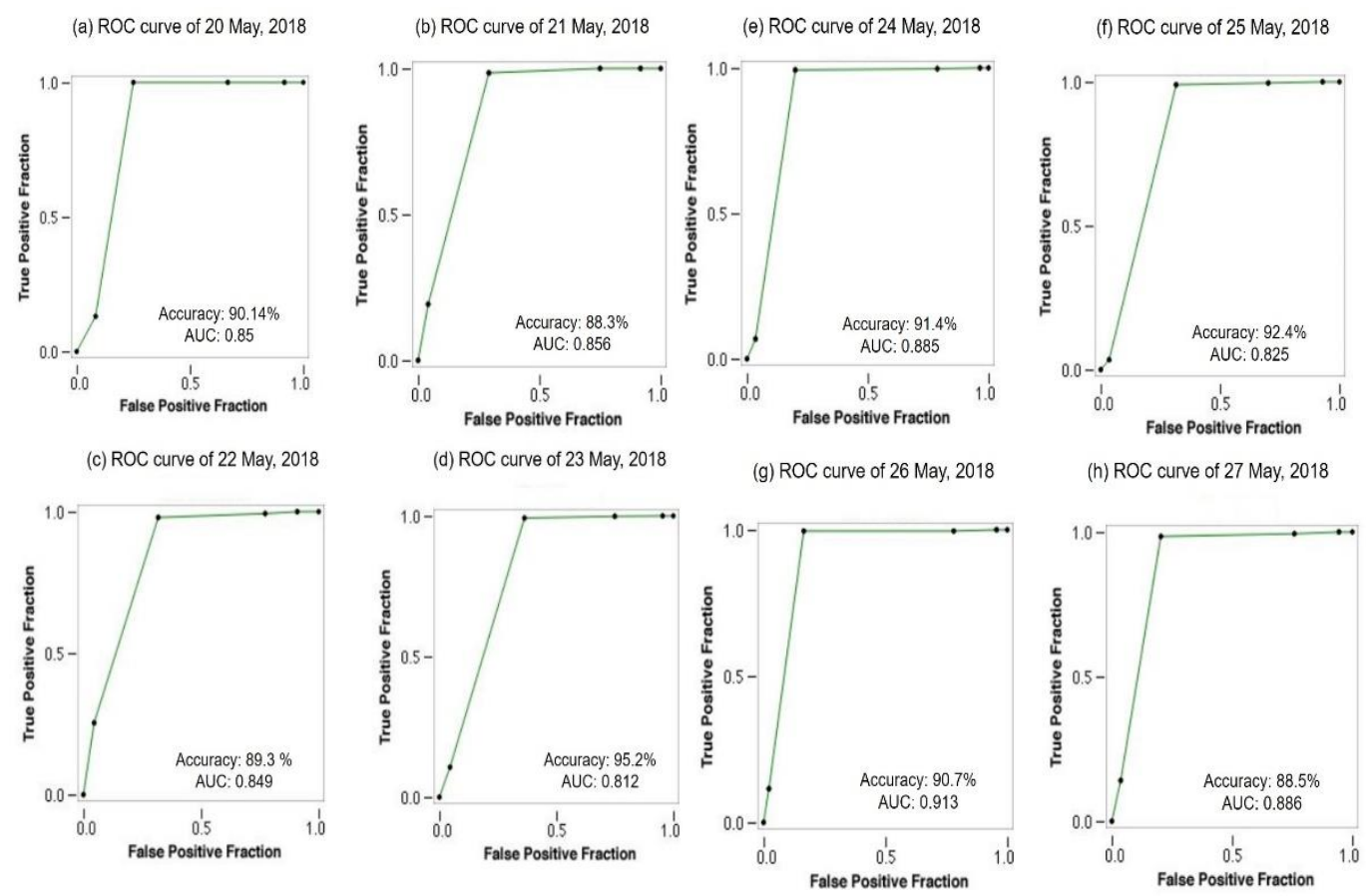

(i) ROC curve of 29 May, 2018

Figure 7. ROC curves and the AUC. (a) 20 May, (b) 21 May, (c) 22 May, (d) 23 May, (e) 24 May, (f) 25 May, (g) 26 May, (h) 27 May, (i) 29 May, 2018. 
acceptable that the most of the fire hotspots should fell in high and very high danger classes rather than other classes of fire danger namely, no fire, low and moderate. It was assumed that the fires fell in high and very high fire danger classes are exactly predicted by the index, otherwise not predicted by the index. Receiver Operating Characteristic (ROC) technique is used for the effective validation of developed Fire Danger Index. ROC represents the probability curve while, the area under ROC curve (AUC) represents the degree of separability between classes and also expresses the quality of a prediction model (Yesilnacar and Topal, 2005). If the value of AUC is close to 1 , then the result of model is excellent, where as the result of model is fairer when the AUC is near to 0.5. Figure 7 shows the ROC curves for the fire episode in 2018 i.e., 20 May 29 May, 2016.

Figure 7, the accuracies and AUC during the fire event (May $20 \sim 29,2018$ ) are: 90.14\%, 0.85 (May 20); 88.3\%, 0.856 (May 21); 89.3\%, 0.849 (May 22); 95.2\%, 0.812 (May 23); 91.4\%, 0.885 (May 24); 92.4\%, 0.825 (May 25); 90.7\%, 0.913 (May 26); 88.5\%, 0.886 (May 27); 86.3\%, 0.879 (May 29). It is clearly evident that the developed Fire Danger Index have the AUC values ranging from 0.81 to 0.91 , that means close to one. If the result of the output is close to 1 , the model performance was good, therefore, the FDI is useful to predict the fire danger accurately over the study area.

\section{Conclusion}

In this study, Forest Fire Danger Index (FFDI) has been developed from the static fire danger index and dynamic danger index. Static fire danger rating index has been developed from the terrain characteristics i.e., fuel type, slope, aspect, elevation, Terrain ruggedness danger index and danger levels have been assigned based on the historical fire data. MODIS Land cover type (MCD12Q1) and ASTER GDEM have been used to develop the static fire danger index. The SFDI is useful to understand the spatial pattern of fire occurrence in the study area and used to determine areas of high fire danger due to the fundamental conditions that leads to fire occurrence. The Dynamic fire danger index (DFDI) has been computed from the Near Real Time satellite datasets such as MODIS Terra Daily surface reflectance product (MOD09), MODIS Terra Daily land surface temperature (MOD11_L2), and ASTER Digital Elevation Model (DEM). Three parameters Potential Surface Temperature (PST), Perpendicular Moisture Index (PMI), and Modified Normalized Difference Fire Index (MNDFI) have been calculated and were used to generate the dynamic fire danger index.

The computed accuracy was ranging from $86 \%$ to $95 \%$ and AUC values ranging from 0.81 to 0.91 , close to one i.e., the FFDI performance was good. Thus, the developed index has the potential for predicting the forest fires using the satellite derived products. The Forest Fire Danger Index has been computed from the near real time datasets, which can be downloaded from the HTTP server after the pass within one hour. The fire danger maps can be disseminating the forest fire danger maps to the forest officials for the controlling activities of forest fires. We are planning to upload the fire danger maps into the web portal in near real time so that fire danger maps can be accessed by public for precaution measures to control forest fires.

Acknowledgements. First author is grateful to Department of Science and Technology (DST), New Delhi, for awarding INSPIRE fellowship. Authors would be thankful to Dr. Prakash Chauhan, Director IIRS, Dr. Senthil Kumar, CSSTEAP Director for their encouragement. The authors acknowledge the MODIS Science team for the Science Algorithms, the Processing Team for producing MODIS data, and the GES DAAC MODIS Data Support Team for making MODIS data available to the user community, NASA REVERB team and FIRMS websites for free MODIS TERRA datasets and Fire data.

\section{References}

Adab, H., Kanniah, K.D., and Solaimani, K. (2013). Modeling forest fire risk in the northeast of Iran using remote 194 sensing and GIS techniques. Natural Hazards, 65(3), 1723-1743. https://doi.org/ 10.1007/s11069-012-0450-8

Akther, M.S., and Hassan, Q.K. (2011). Remote sensing-based assessment of fire danger conditions over boreal forest. IEEE Journal of Selected Topics in Applied Earth Observations and Remote Sensing, 4(4), 992-999. https://doi.org/10.1109/JSTARS. 2011.2165940

Alexander, M.E., and Cole, F.V. (2001). Rating fire danger in Alaska ecosystems. Fireline, 12, 2-3.

Alexander, M.E., and Fogarty, L.G. (2002). A pocket card for predicting fire behaviour in grasslands under severe burning conditions.

Alexander, M.E., Stocks, B.J., and Lawson, B.D. (1996). The Canadian forest fire danger rating system.

Babu K.V., S., Roy, A., and Prasad, P.R. (2016a). Forest fire risk modeling in Uttarakhand Himalaya using TERRA satellite datasets. European Journal of Remote Sensing, 49(1), 381-395. https:// doi.org/10.5721/EuJRS20164921

Babu, K.S., Roy, A., and Prasad, P.R. (2016b). Developing the static fire danger index using geospatial technology. 2016 2nd International Conference on Contemporary Computing and Informatics (IC3I), pp. 558-563. IEEE. https://doi.org/10.1109/IC 3I.2016.7918026

Bajocco, S., Pezzatti, G.B., Mazzoleni, S., and Ricotta, C. (2010). Wildfire seasonality and land use: when do wildfires prefer to burn? Environmental Monitoring and Assessment, 164(1-4), 445-452. https://doi.org/10.1007/s10661-009-0905-x

Bisquert, M., Caselles, E., Sánchez, J.M., and Caselles, V. (2012). Application of artificial neural networks and logistic regression to the prediction of forest fire danger in Galicia using MODIS data. International Journal of Wildland Fire, 21(8), 1025-1029. https://doi.org/10.1071/WF11105

Bisquert, M., Sánchez, J. M., and Caselles, V. (2014). Modeling fire danger in Galicia and Asturias (Spain) from MODIS images. Remote Sensing, 6(1), 540-554. https://doi.org/10.3390/rs6010540

Carlson, T. (2007). An overview of the" triangle method" for estimating surface evapotranspiration and soil moisture from satellite imagery. Sensors, 7(8), 1612-1629. https://doi.org/10.33 90/s7081612

Ceccato, P., Gobron, N., Flasse, S., Pinty, B., and Tarantola, S. (2002). Designing a spectral index to estimate vegetation water content from remote sensing data: Part 1: Theoretical approach. Remote 
Sensing of Environment, 82(2-3), 188-197. https://doi.org/10.1016/ S0034-4257(02)00037-8

Chowdhury, E.H., and Hassan, Q.K. (2015). Development of a new daily-scale forest fire danger forecasting system using remote sensing data. Remote Sensing, 7(3), 2431-2448. https://doi.org/ $10.3390 /$ rs 70302431

Chuvieco, E., Giglio, L., and Justice, C. (2008). Global characterization of fire activity: toward defining fire regimes from Earth observation data. Global change biology, 14(7), 1488-1502. https://doi.org/10.1111/j.1365-2486.2008.01585.x

Chuvieco, E., Martin, M. P., and Palacios, A. (2002). Assessment of different spectral indices in the red-near-infrared spectral domain for burned land discrimination. International Journal of Remote Sensing, 23(23), 5103-5110. https://doi.org/10.1080/01431160210 153129

Dasgupta, S., Qu, J.J., Hao, X., and Bhoi, S. (2007). Evaluating remotely sensed live fuel moisture estimations for fire behavior predictions in Georgia, USA. Remote Sensing of Environment, 108(2), 138-150. https://doi.org/10.1016/j.rse.2006.06.023

De Groot, W.J., Field, R.D., Brady, M.A., Roswintiarti, O., and Mohamad, M. (2007). Development of the Indonesian and Malaysian fire danger rating systems. Mitigation and Adaptation Strategies for Global Change, 12(1), 165. https://doi.org/10.1007/ s11027-006-9043-8

Dennison, P.E., Roberts, D.A., Peterson, S.H., and Rechel, J. (2005). Use of normalized difference water index for monitoring live fuel moisture. International Journal of Remote Sensing, 26(5), 10351042. https://doi.org/10.1080/0143116042000273998

Earthdata, https://earthdata.nasa.gov/earth-observation-data/near-real -time. accessed on Jan 20, 2018.

EijiNunohiro, Katayama, K., Mackin, K.J., and Park, J.G. (2007). Forest and field fire search system using MODIS data. JACIII, 11(8), 1043-1048. https://doi.org/10.20965/jaciii.2007.p1043

Eskandari, S., and Chuvieco, E. (2015). Fire danger assessment in Iran based on geospatial information. 196 International Journal of Applied Earth Observation and Geoinformation, 42, 57-64. https://doi.org/10.1016/j.jag.2015.05.006

Fennessy, M.J., and Shukla, J. (1999). Impact of initial soil wetness on seasonal atmospheric prediction. Journal of Climate, 12(11), 31673180. https://doi.org/10.1175/1520-0442(1999)012<3167:IO ISWO $>2.0 . \mathrm{CO} ; 2$

Granström, A. (2001). Fire management for biodiversity in the European boreal forest. Scandinavian Journal of Forest Research, 16(S3), 62-69. https://doi.org/10.1080/028275801300090627

Guangmeng, G., and Mei, Z. (2004). Using MODIS land surface temperature to evaluate forest fire risk of northeast China. IEEE Geoscience and Remote sensing letters, 1(2), 98-100. https:// doi.org/10.1109/LGRS.2004.826550

Hari, P., and Nöjd, P. (2009). The effect of temperature and PAR on the annual photosynthetic production of Scots pine in northern Finland during 1906-2002. Boreal Environment Research, 5-18.

Hassan, Q.K., and Bourque, C.P.A. (2009). Potential species distribution of balsam fir based on the integration of biophysical variables derived with remote sensing and process-based methods. Remote Sensing, 1(3), 393-407. https://doi.org/10.3390/rs1030393

Hassan, Q.K., Bourque, C.P.A., Meng, F.R., and Cox, R.M. (2007). A wetness index using Terrain-corrected surface temperature and normalized difference vegetation index derived from standard MODIS products: an evaluation of its use in a humid forestdominated region of eastern Canada. Sensors, 7(10), 2028-2048. https://doi.org/10.3390/ s7102028

Huesca, M., Litago, J., Palacios-Orueta, A., Montes, F., SebastiánLópez, A., and Escribano, P. (2009). Assessment of forest fire seasonality using MODIS fire potential: A time series approach.
Agricultural and Forest Meteorology, 149(11), 1946-1955. https:// doi.org/10.1016/j.agrformet.2009.06.022

ISFR. (2015). State of Forest Report. Forest Survey of India, Dehradun. pp. 55

Leblon, B., García, P.A.F., Oldford, S., Maclean, D.A., and Flannigan, M. (2007). Using cumulative NOAA-AVHRR spectral indices for estimating fire danger codes in northern boreal forests. International Journal of Applied Earth Observation and Geoinformation, 9(3), 335-342. https://doi.org/10.1016/j.jag.2006. 11.001

Leblon, B., San-Miguel-Ayanz, J., Bourgeau-Chavez, L., and Kong, M. (2017). Remote Sensing of Wildfires. Land Surface Remote Sensing, 55-95. https://doi.org/10.1016/B978-1-78548-105-5.500 03-7

Lee, B.S., Alexander, M.E., Hawkes, B.C., Lynham, T.J., Stocks, B.J., and Englefield, P. (2002). Information systems in support of wildland fire management decision making in Canada. Computers and Electronics in Agriculture, 37(1-3), 185-198. https://doi.org/10. 1016/S0168-1699(02)00120-5

LPDAAC. https://lpdaac.usgs.gov/ accessed on Feb 18, 2018.

Maeda, E.E., Arcoverde, G.F., Pellikka, P.K., Shimabukuro, Y.E. (2011). Fire risk assessment in the Brazilian 192 Amazon using MODIS imagery and change vector analysis. Applied Geography, 31(1), 76-84. https://doi.org/10.1016/j.apgeog.2010.02.004

Maffei, C., and Menenti, M. (2014). A MODIS-based perpendicular moisture index to retrieve leaf moisture content of forest canopies. International Journal of Remote Sensing, 35(5), 1829-1845. https://doi.org/10.1080/01431161.2013.879348

McArthur, A.G. (1958). The preparation and use of fire danger tables. In Proceeding of Fire Weather Conference, Melbourne.

Mölders, N. (2008). Suitability of the Weather Research and Forecasting (WRF) model to predict the June 2005 fire weather for Interior Alaska. Weather and Forecasting, 23(5), 953-973. https://doi.org/10.1175/2008WAF2007062.1

Moran, M.S., Peters-Lidard, C.D., Watts, JM., and McElroy, S. (2004). Estimating soil moisture at the watershed scale with satellite-based radar and land surface models. Canadian Journal of Remote Sensing, 30(5), 805-826. https://doi.org/10.5589/m04-043

Near Real Time data ftp server. ftp://nrt3.modaps.eosdis.nasa.gov/ accessed on Apr 12, 2018

Nieto, H., Sandholt, I., Aguado, I., Chuvieco, E., and Stisen, S. (2011). Air temperature estimation with MSG-SEVIRI data: Calibration and validation of the TVX algorithm for the Iberian Peninsula. Remote Sensing of Environment, 115(1), 107-116. https://doi.org/ 10.1016/j.rse.2010.08.010

Oldford, S., Leblon, B., Maclean, D., and Flannigan, M. (2006). Predicting slow-drying fire weather index fuel moisture codes with NOAA-AVHRR images in Canada's northern boreal forests. International Journal of Remote Sensing, 27(18), 3881-3902. https://doi.org/10.1080/01431160600784234

Peterson, S.H., Roberts, D.A., and Dennison, P.E. (2008). Mapping live fuel moisture with MODIS data: A multiple regression approach. Remote Sensing of Environment, 112(12), 4272-4284. https://doi.org/10.1016/j.rse.2008.07.012

Petropoulos, G., Carlson, T.N., Wooster, M.J., and Islam, S. (2009). A review of Ts/VI remote sensing-based methods for the retrieval of land surface energy fluxes and soil surface moisture. Progress in Physical Geography, 33(2), 224-250. https://doi.org/10.1177/0309133309338997

Safi, Y., and Bouroumi, A. (2013). Prediction of forest fires using artificial neural networks. Applied Mathematical Sciences, 7(6), 271-286. https://doi.org/10.12988/ams.2013.13025

San-Miguel-Ayanz, J., Carlson, J.D., Alexander, M., Tolhurst, K., Morgan, G., Sneeuwjagt, R., and Dudley, M. (2003). Current methods to assess fire danger potential. Wildland Fire Danger Estimation and Mapping: The Role of Remote Sensing Data, 21-61. https://doi.org/10.1142/9789812791177_0002 
Schlobohm, P., and Brain, J. (2002). Gaining an Understanding of the National Fire Danger Rating System. National Wildfire Coordinating Group, PMS, 932.

Schneider, P., Roberts, D.A., and Kyriakidis, P.C. (2008). A VARIbased relative greenness from MODIS data for computing the Fire Potential Index. Remote Sensing of Environment, 112(3), 1151-1167. https://doi.org/10.1016/j.rse.2007.07.010

Sow, M., Mbow, C., Hély, C., Fensholt, R., and Sambou, B. (2013). Estimation of herbaceous fuel moisture content using vegetation indices and land surface temperature from MODIS data. Remote Sensing, 5(6), 2617-2638. https://doi.org/10.3390/rs5062617

Stocks B. J., Lawson B.D., Alexander M.E., Van Wagner C.E., McAlpine R.S., Lynham T.J., Dube D.E, (1989). The Canadian Forest Fire Danger Rating System: an overview. The Forestry Chronicle, 65, 450-457. https://doi.org/10.5558/tfc65450-6

Stow, D., Niphadkar, M., and Kaiser, J. (2005). MODIS-derived visible atmospherically resistant index for monitoring chaparral moisture content. International Journal of Remote Sensing, 26(17), 3867-3873. https://doi.org/10.1080/01431160500185342

Taylor, S.W., and Alexander, M.E. (2006). Science, technology, and human factors in fire danger rating: the Canadian experience. International Journal of Wildland Fire, 15(1), 121-135. https://doi.org/10.1071/WF05021

Van Nest, T.A., and Alexander, M.E. (1999). Systems for rating fire danger and predicting fire behavior used in Canada. In Actas de National Interagency Fire Behavior Workshop (Vol. 1).

Vermote, E.F., El Saleous, N.Z., and Justice, C.O. (2002). Atmospheric correction of MODIS data in the visible to middle infrared: First results. Remote Sensing of Environment, 83(1-2), 97-111. https://doi.org/10.1016/S0034-4257(02)00089-5

Vidal, A., and Devaux-Ros, C. (1995). Evaluating forest fire hazard with a Landsat TM derived water stress index. Agricultural and Forest Meteorology, 77(3-4), 207-224. https://doi.org/10.1016/0 168-1923(95)02262-V

Viegas, D. X., Bovio, G., Ferreira, A., Nosenzo, A., and Sol, B. (1999). Comparative study of various methods of fire danger evaluation in southern Europe. International Journal of Wildland Fire, 9(4), 235246. https://doi.org/10.1071/WF00015

Wang, L. and Qu, J.J. (2007). NMDI: A normalized multi-band drought index for monitoring soil and vegetation moisture with satellite remote sensing. Geophysical Research Letters, 34(20). https:// doi.org/10.1029/2007GL031021

Wang, L. and Qu, J.J. (2009). Satellite remote sensing applications for surface soil moisture monitoring: A review. Frontiers of Earth Science in China, 3(2), 237-247. https://doi.org/10.1007/s11707009-0023-7

Wang, L., Qu, J.J., and Hao, X. (2008). Forest fire detection using the normalized multi-band drought index (NMDI) with satellite measurements. Agricultural and Forest Meteorology, 148(11), 1767-1776. https://doi.org/10.1016/j.agrformet.2008.06.005

Yesilnacar, E., and Topal, T. (2005). Landslide susceptibility mapping: a comparison of logistic regression and neural networks methods in a medium scale study, Hendek region (Turkey). Engineering Geology, 79(3-4), 251-266. https://doi.org/10.1016/j.enggeo.200 5.02 .002 